\title{
Microwave plasma assisted preparation of Pd-nanoparticles with controlled dispersion on woven activated carbon fibres
}

\author{
Pavel Korovchenko, Albert Renken, Lioubov Kiwi-Minsker* \\ Ecole Polytechnique Fédéral de Lausanne, LGRS-EPFL, CH-1015 Lausanne, Switzerland
}

Available online 31 March 2005

\begin{abstract}
The low-pressure cold microwave (MW) plasma is shown as an efficient method to increase acidity of the ACF within less than 1 min treatment without affecting the fibre morphology and strength. The ion-exchange capacity was 1.6 times higher compared to the non-treated ACF sample. Selective removal of the carboxylic groups from the ACF surface by the air-MW-plasma allows to keep the phenolic groups intact. Palladium was deposited on ACF from $\left[\mathrm{Pd}\left(\mathrm{NH}_{3}\right)_{4}\right] \mathrm{Cl}_{2}$ solution via ion-exchange with the protons of the phenolic surface groups. Surface phenolic groups were able to chemically anchor Pd in cationic form, leading after reduction in $\mathrm{H}_{2}$ to small $\mathrm{Pd}^{\circ}$ nanoparticles $(<3 \mathrm{~nm})$. The Pd dispersion was measured by $\mathrm{CO}$ pulse adsorption and confirmed by the TEM analysis. Heating of the $\mathrm{Pd} / \mathrm{ACF}$ catalysts in $\mathrm{H}_{2}$ at $573-$ $773 \mathrm{~K}$ is necessary to reduce $\mathrm{Pd}(\mathrm{II})$ to $\mathrm{Pd}^{\circ}$. This reduction can be also achieved by the $\mathrm{H}_{2}-\mathrm{MW}$-plasma treatment in less than 1 min with the corresponding saving of energy.
\end{abstract}

(C) 2005 Elsevier B.V. All rights reserved.

Keywords: Activated carbon fibres; Pd nano-particles; Cold micro-wave plasma; Surface functional groups; TPD analysis

\section{Introduction}

Activated carbon fibres (ACF) in the form of woven fabrics recently have been shown as suitable catalytic supports for noble metals [1-5]. These materials have high specific surface area up to $3000 \mathrm{~m}^{2} / \mathrm{g}$ and allow high loading of metal nano-particles ensuring an increased specific activity. To achieve high metal dispersion, the carbon fabric requires a pre-treatment to increase the concentration of the surface functional groups. These pre-treatments like gasphase oxidation by $\mathrm{CO}_{2}$ or $\mathrm{O}_{2}$, steaming or wet chemical oxidation by $\mathrm{H}_{2} \mathrm{O}_{2}, \mathrm{HNO}_{3}, \mathrm{KMnO}_{4}, \mathrm{NaOCl}$ and $\left(\mathrm{NH}_{4}\right)_{2} \mathrm{~S}_{2} \mathrm{O}_{8}$ have been carried out with different carbons leading to the formation of oxygen containing groups like carboxyl, carbonyl, phenol, quinone and lactones on the carbon surface [6-10]. In a previous publication [11] it was shown that phenolic groups were responsible for the high dispersion of noble metals (Pd, Pt or $\mathrm{Au}$ ) on ACF deposited by cationic ion-exchange from aqueous solutions of the metal ammonia complexes. Carboxylic surface groups on ACF fabrics were

\footnotetext{
* Corresponding author. Tel.: +41 216933182.

E-mail address: lioubov.kiwi-minsker@epfl.ch (L. Kiwi-Minsker).
}

observed to lead to the formation of relatively big $(>10 \mathrm{~nm})$ metal particles, while surface phenolic groups were able to chemically anchor gold ions that after reduction in $\mathrm{H}_{2}$ lead to small $\mathrm{Au}^{\circ}$ nanoparticles $(<5 \mathrm{~nm})$ on ACF. The surface groups can be controlled via selective decomposition by heating in an inert atmosphere [11-14]. However, the traditional pre-treatments are time and energy consuming and often damage the surface of carbon materials. This is especially important in the case of the ACF due to the specific morphology of carbon fibres, which should be preserved.

During the last 10 years low temperature plasma techniques have been applied for the surface modification of carbons. Microwave (MW) plasma is used at temperatures as low as room temperature. This allows treating carbon surfaces to meet specific requirements without affecting the fibre textural characteristics and strength.

Thus, Boudou et al. [15] confirmed by SEM and STM analysis that the pitch-based carbon fibres treated in low pressure (1.0 mbar) oxygen MW plasma during 1-5 min keep their structure and diameter. At the same time, the carbon surface is cleaned from contaminations and the specific surface area (SSA) is increased due to improved roughness. 
The type of gas used for MW-plasma treatment is known to affect the surface modification. For example, oxygen or air plasma leads to the oxidation of carbon surface [15-27]. Nitrogen and ammonia plasmas introduce $\mathrm{C} / \mathrm{N}$ functionality on carbon surface [26-28]. Argon plasma activates the carbon surface due to etching and "cleaning" processes [29-31]. Hydrogen plasma has been used for the cleaning of carbons to improve the SSA [28]. Moreover, it is possible to obtain different surface effects by varying the plasma parameters (power, treatment time, and gas pressure) without changing the gas. For example, oxygen or air MW-plasma creates on the carbon surface oxygen containing groups under low power treatment within short time $[15,26,27]$, but cleans the surface with the partial elimination of the oxygen functionality under high power MW radiation during long exposures $[15,22]$.

Cold MW plasma has been rarely applied for the preparation of catalytically active particles of noble metals on various carriers. The only reports found concern the formation of Pt and Au nanoparticles in zeolites [32-34].

In this study, cold MW-plasma under oxygen, air or hydrogen at low pressure was applied for the surface modification of ACF woven fabrics. The selective regulation of the surface functionality to control the dispersion of Pd nano-particles deposited via ion-exchange/adsorption from different Pd-containing precursors was the aim of this work. It is well known that the catalyst post-treatment is necessary for metal complex decomposition and metal particles activation. The high temperature reduction by hydrogen is used for this purpose leading to the metal sintering with a decrease in the observed catalytic activity. The high reductive capacity of cold plasma under $\mathrm{H}_{2}$ has been reported [32,33,35]. The catalyst post-treatment by oxygen cold plasma is also known for the precursor complex destruction $[34,36]$. In this work, the $\mathrm{O}_{2}$ and $\mathrm{H}_{2}$ MW-plasma catalyst post-treatment is further investigated in detail. We present hereby the first evidence on the MW-plasma assisted preparation of structured Pd/ACF catalysts where the combination of the support pre-treatment with the catalyst post-treatment by cold MW-plasma is used for the controlling of Pd dispersion.

\section{Experimental}

\subsection{Materials}

The ACF of polyacrylonitrile (PAN) in the form of plain woven fabrics (AW1101, KoTHmex, Taiwan Carbon Technology Co.) were used as supports. The fabrics are woven from the long threads of ca. $0.5 \mathrm{~mm}$ in diameter consisting of a bundle of elementary filaments of 3-5 $\mu \mathrm{m}$ in diameter. The elemental composition of the ACF was $>99.9 \%$ of carbon as measured by atomic absorption spectroscopy (AAS). The tetra-ammine-palladium(II) chloride monohydrate [Pd $\left.\left(\mathrm{NH}_{4}\right)_{3}\right] \mathrm{Cl}_{2} \cdot \mathrm{H}_{2} \mathrm{O}$ "p.a." was used as received (Aldrich Chem. Co., Reactolab S.A., Switzerland). The palladium(II) chloride anhydrous $\left(\mathrm{PdCl}_{2}\right)$ and the sodium chloride $(\mathrm{NaCl})$ were "p.a." from Fluka (Buchs, Switzerland). The $\mathrm{Na}_{2} \mathrm{PdCl}_{4}$ was prepared by mixing equivalent amounts of $\mathrm{PdCl}_{2}$ and $\mathrm{NaCl}$ in aqueous solution. All gases in this study were $>99.9998 \%$ (CarbaGas, Switzerland).

\subsection{Modification of the ACF support}

\subsubsection{The ACF treatment by MW-plasma}

The ACF treatment by MW-plasma was performed with the MW-plasma apparatus of Vacotec Swiss Co. and used at $2.45 \mathrm{GHz}$. The power was varied from 100 to $600 \mathrm{~W}$, the reaction times were changed from 10 to $180 \mathrm{~s}$, the gas flow was between 20 and $100 \mathrm{ml} / \mathrm{min}$, and the gas pressure varied from 0.02 to 2 mbar. Before the sample treatments the plasma MW-chamber was evacuated for $2 \mathrm{~h}$ up to 0.001 mbar. The MW-plasma in oxygen $\left(\mathrm{O}_{2}-\mathrm{MW}\right.$-plasma $)$ and MW-plasma in air (air-MW-plasma) were used to oxidize the ACF surface. The MW-plasma in hydrogen $\left(\mathrm{H}_{2}-\right.$ MW-plasma) was applied to replace the traditional high temperature reduction of $\mathrm{Pd}$-ions by $\mathrm{H}_{2}$.

The ACF without any treatment is denoted as $\mathrm{ACF}_{\text {original }}$. Two ACF samples treated in a traditional way were used for the comparison of the textural and surface chemical properties with the plasma-treated ACF. One sample, $\mathrm{ACF}_{\mathrm{HNO}_{3}}$, was boiled in aqueous $\mathrm{HNO}_{3}(15$ vol.\%) for $1 \mathrm{~h}$, rinsed with distilled water until neutral $\mathrm{pH}$, air-dried for $3 \mathrm{~h}$ at room temperature and finally for $15 \mathrm{~h}$ at $393 \mathrm{~K}$. The sample $\mathrm{ACF}_{\mathrm{He}, 1273}$ was obtained by heating the $\mathrm{ACF}_{\text {original }}$ in $\mathrm{He}(1273 \mathrm{~K}, 100 \mathrm{ml} / \mathrm{min}, 1 \mathrm{~h})$.

\subsection{Preparation of Pd/ACF catalysts}

Pd deposition was performed via ion-exchange/adsorption from two different precursors. The ACF fabrics $(\sim 1.6 \mathrm{~g})$ were immersed in stirred $\left[\mathrm{Pd}\left(\mathrm{NH}_{4}\right)_{3}\right] \mathrm{Cl}_{2}$ or $\mathrm{Na}_{2} \mathrm{PdCl}_{4}$ aqueous solutions for $5 \mathrm{~h}$. The $\mathrm{pH}$ of the solution was kept neutral without any alkali addition. The Pd concentrations were varied from 1 to $5 \mathrm{wt} . \%$. After Pd-ions deposition, the fabrics were rinsed with distilled water, air-dried for $3 \mathrm{~h}$ at room temperature and finally for $15 \mathrm{~h}$ at $393 \mathrm{~K}$.

\subsubsection{Pd/ACF catalysts activation}

$\mathrm{Pd} / \mathrm{ACF}$ catalysts activation was carried out by MWplasma post-treatment in oxygen or hydrogen in order to eliminate ammonium or chlorine-ions present in $\mathrm{Pd}$ complex. The MW-plasma treatment was used as described in Section 2.2. In order to prevent the Pd particles sintering, the MW-plasma oxidative post-treatment was performed in four consecutive cycles for $15 \mathrm{~s}$ spaced 5 min apart.

\subsection{Catalysts characterization}

\subsubsection{The specific surface areas}

The SSA were measured using $\mathrm{N}_{2}$ adsorption-desorption at $77 \mathrm{~K}$ by a Sorptomatic 1990 instrument (Carlo Erba). The 
samples were heated in vacuum at $523 \mathrm{~K}$ for $2 \mathrm{~h}$ before the measurements. The SSA of the samples was calculated employing the BET method. The Dollimore/Heal method was applied for pore volume and pore-size calculation. The pore size distribution was in the range between 1 and $9 \mathrm{~nm}$ suggesting a micro- and meso-porosity for the examined materials.

\subsubsection{The temperature programmed decomposition (TPD) in $\mathrm{He}$}

The TPD in He was carried out to identify the surface functional groups and for characterization of surface acidity using a Micromeritics AutoChem 2910 analyzer. For the TPD measurements $0.05 \mathrm{~g}$ of ACF sample was placed in a quartz plug-flow reactor and purged in He flow $(20 \mathrm{ml} / \mathrm{min})$ for $30 \mathrm{~min}$ at room temperature. Then, the temperature was increased up to $1273 \mathrm{~K}$ with a ramp of $10 \mathrm{~K} / \mathrm{min}$. The control of a reaction temperature was performed by a thermocouple placed in the catalytic bed. The TPD products were analyzed by ThermoStar-200 quadrupole "on-line" mass-spectrometer (Pfeiffer Vacuum) calibrated with gas mixtures of known compositions. The intensity of the following peaks was measured simultaneously: 2, 4, 15, 18, 28, 30, 32 and $44 \mathrm{~m} / \mathrm{e}$.

\subsubsection{XPS analysis}

XPS analysis by Axic Ultra ASCA system (Kratos, Manchester) with monochronated $\mathrm{Al} \mathrm{K} \alpha$ radiation $(1486.6 \mathrm{eV})$ and an X-ray power of $150 \mathrm{~W}$ was used to determin the surface chemical composition.

\subsubsection{The atomic absorption spectroscopy}

The atomic absorption spectroscopy was carried out via Shimadzu AA-6650 with air-acetylene flame. The amount of deposited Pd was controlled by the analysis of the residual solution of Pd precursor and by chemical analysis of the $\mathrm{Pd} /$ ACF samples. For the chemical analysis the $\mathrm{Pd} / \mathrm{ACF}$ samples were heated in air at $973 \mathrm{~K}$ for $2 \mathrm{~h}$ in order to burn out the carbon and the obtained ashes $(<0.1 \mathrm{wt} . \%)$ were dissolved in hot aqua regia containing $\mathrm{HF}$.

\subsubsection{The SSA of $P d$ and its dispersion}

The SSA of $\mathrm{Pd}$ and its dispersion were measured by $\mathrm{CO}$ pulse adsorption ( 3 vol.\% $\mathrm{CO}$ in $\mathrm{He}$ ) at $323 \mathrm{~K}$ using a Micromeritics AutoChem 2910 analyzer. The samples $(0.05 \mathrm{~g})$ were pre-treated in a flow of $\mathrm{He}(100 \mathrm{ml} / \mathrm{min})$ at $423 \mathrm{~K}$ during $1 \mathrm{~h}$ and subsequently in $\mathrm{H}_{2}(100 \mathrm{ml} / \mathrm{min})$ flow at $423 \mathrm{~K}$ during $1 \mathrm{~h}$. A Pd density of $12.02 \mathrm{~g} / \mathrm{cm}^{3}$ and a stoichiometry factor $\mathrm{SF}_{\mathrm{Pd}}=\mathrm{CO} / \mathrm{Pd}$ of 1.667 were taken for the $\mathrm{SSA}_{\mathrm{Pd}}$ calculation.

\subsubsection{The high resolution transmission electron microscopy (HRTEM)}

The high resolution transmission electron microscopy was used for the investigation of surface morphology via Philips CM300UT FEG with $300 \mathrm{kV}$ field emission gun,
$0.65 \mathrm{~mm}$ spherical aberration and $0.17 \mathrm{~mm}$ resolution at Scherzer defocus. The images were recoded on a Gatan 797 slow-scan CCD camera $(1024 \times 1024$ pixels $)$ and processed with theGatan Digital Micrograph 3.4.4 software to measure the distances and the angles between the atomic planes.

\section{Results and discussion}

\subsection{Effect of MW-plasma treatment on ACF texture}

One of the objectives of the present study is to modify by cold MW-plasma the textural characteristics of ACF fabrics and their surface functionality. The effect of different pretreatments on the SSA of ACF supports is presented in Table 1 . The SSA is seen to depend strongly on the treatment varying from 600 to $1050 \mathrm{~m}^{2} / \mathrm{g}$. The liquid phase oxidation by boiling $\mathrm{HNO}_{3}$ decreases the $\mathrm{SSA}$ of the $\mathrm{ACF}_{\text {original }}$ sample from 925 to $613 \mathrm{~m}^{2} / \mathrm{g}$. This indicates that the ACF surface oxidation leads to the decrease in micropores when introducing oxygen functionality. These observations agree with the reported results $[37,38]$. ACF treatment in $\mathrm{He}$ at $973 \mathrm{~K}$ and at $1273 \mathrm{~K}$ during $1 \mathrm{~h}$ slightly decreases the SSA from 925 to $\sim 820 \mathrm{~m}^{2} / \mathrm{g}$. This suggests partial surface destruction due to higher temperatures. In contrast, the MWplasma treatments slightly increase the SSA if compared to the $\mathrm{ACF}_{\text {original }}$ independently of the nature of the gas used. This may be explained by the surface cleaning with simultaneous opening of micro-pores at the external surface of the sample [15]. At the same time it is important to note that the internal structure of the sample meso- and microporosity is not modified by the plasma treatment, even under the conditions used for the high degree of the ACF burn-off [18].

The adsorption capacities for $\left[\mathrm{Pd}\left(\mathrm{NH}_{3}\right)_{4}\right] \mathrm{Cl}_{2}$ complex on the ACF supports show in Table 1 that the surface functionality is strongly affected. Thus, in spite of the decreased porosity of the $\mathrm{ACF}_{\mathrm{HNO}_{3}}$ sample as compared to the $\mathrm{ACF}_{\text {original }}$, the amount of the $\mathrm{Pd}$ adsorbed is two-fold higher. The chemical properties of activated carbons are

Table 1

Specific surface area and adsorption capacity of the ACF supports after different pre-treatments

\begin{tabular}{|c|c|c|c|}
\hline ACF supports & ACF treatment & $\begin{array}{l}\text { Surface area } \\
\text { B.E.T. }\left(\mathrm{m}^{2} / \mathrm{g}\right)\end{array}$ & $\begin{array}{l}\text { Adsorption of } \\
\mathrm{Pd}^{\mathrm{a}}(\mathrm{mmol} / \mathrm{g})\end{array}$ \\
\hline $\mathrm{ACF}_{\text {original }}$ & No & 925 & 0.13 \\
\hline $\mathrm{ACF}_{\mathrm{HNO}_{3}}$ & Boiling in $\mathrm{HNO}_{3}$ & 613 & 0.24 \\
\hline $\mathrm{ACF}_{\mathrm{He}, 973}$ & $\begin{array}{l}\text { Heating in } \mathrm{He} \text { at } \\
973 \mathrm{~K}, 1 \mathrm{~h}\end{array}$ & 822 & - \\
\hline $\mathrm{ACF}_{\mathrm{He}, 1273}$ & $\begin{array}{l}\text { Heating in } \mathrm{He} \text { at } \\
1273 \mathrm{~K}, 1 \mathrm{~h}\end{array}$ & & 0.05 \\
\hline $\mathrm{ACF}_{\text {air-MW-plasma }}$ & Air-MW-plasma & 1018 & 0.21 \\
\hline $\mathrm{ACF}_{\mathrm{O}_{2}-\mathrm{MW} \text {-plasma }}$ & $\mathrm{O}_{2}-\mathrm{MW}$-plasma & 959 & - \\
\hline $\mathrm{ACF}_{\mathrm{H}_{2}-\mathrm{MW} \text {-plasma }}$ & $\mathrm{H}_{2}-\mathrm{MW}$-plasma & 1049 & - \\
\hline
\end{tabular}

${ }^{\mathrm{a}}$ In the form of $\left[\mathrm{Pd}\left(\mathrm{NH}_{3}\right)_{4}\right] \mathrm{Cl}_{2}$ complex. 
known to be very important for the metal deposition because the adsorption capacity is determined by (a) porous structure and (b) by the chemical nature of the surface, in particular by the surface oxygen groups. Therefore, this question warrens a detail study.

\subsection{Effect of MW-plasma treatment on ACF surface functional groups}

It is well known that each type of surface oxygen group decomposes to the well defined products, e.g., that $\mathrm{CO}_{2}$ derives from carboxyl, lactone/lactol and carboxyl anhydride groups, and $\mathrm{CO}$ is formed by decomposition of carboxyl anhydride, carbonyl/quinone, phenolic and ethertype oxygen groups $[6,12]$. Total amounts of $\mathrm{CO}$ and $\mathrm{CO}_{2}$ produced during TPD analysis can be used for the quantitative and qualitative characterization of the carbon surface functional groups $[6,7]$.

\subsubsection{The influence of the gas nature applied during $M W$-plasma treatment}

The influence of the gas nature applied during MWplasma treatment on the ACF surface functionality was studied by TPD analysis. The ACF samples pre-treated by MW-plasma in air, $\mathrm{O}_{2}$ and $\mathrm{H}_{2}$ were compared with the ACF samples modified by $\mathrm{HNO}_{3}$ and by $\mathrm{He}$ at high temperature. Fig. 1 presents the comparative bar diagram of total amounts of $\mathrm{CO}$ and $\mathrm{CO}_{2}$ obtained during TPD. The $\mathrm{HNO}_{3}$ wet oxidation produces ACF surfaces with a high total acidity. Thus, the total amount of $\mathrm{CO}_{2}$ increases about 10 times and the total amount of $\mathrm{CO}$ is about 2.5-fold higher if compared with the $\mathrm{ACF}_{\text {original. The thermal treatment in inert }}$ atmosphere $(\mathrm{He})$ completely eliminates the precursor groups leading to $\mathrm{CO}_{2}$ evolution during TPD and drastically decreases the oxygen species able to produce $\mathrm{CO}$. The same tendency is observed also for the sample of ACF treated by $\mathrm{O}_{2}-\mathrm{MW}$-plasma ( $600 \mathrm{~W}, 0.2 \mathrm{mbar}, 30 \mathrm{~s}$ ). In contrast to this, the $\mathrm{H}_{2}-\mathrm{MW}$-plasma treatment ( $600 \mathrm{~W}, 0.5 \mathrm{mbar}, 30 \mathrm{~s}$ ) gives the biggest SSA and does not change the surface functionality. The results obtained for air-MW-plasma treatment are the most interesting. In this case, the total
Table 2

Parameters of the air-MW-plasma treatment of the ACF-support and the amounts of $\mathrm{CO}$ and $\mathrm{CO}_{2}$ evolved during TPD in $\mathrm{He}$

\begin{tabular}{|c|c|c|}
\hline & $\mathrm{CO}(\mathrm{mmol} / \mathrm{g})$ & $\mathrm{CO}_{2}(\mathrm{mmol} / \mathrm{g})$ \\
\hline \multicolumn{3}{|c|}{ Treatment time (s) } \\
\hline 15 & 3.16 & 0.52 \\
\hline 30 & 3.26 & 0.55 \\
\hline 60 & 3.20 & 0.54 \\
\hline \multicolumn{3}{|c|}{ Plasma power: $300 \mathrm{~W}$, gas pressure: $0.2 \mathrm{mbar}$} \\
\hline \multicolumn{3}{|c|}{ Gas pressure (mbar) } \\
\hline 0.01 & 3.20 & 0.48 \\
\hline 0.2 & 3.26 & 0.55 \\
\hline \multicolumn{3}{|c|}{ Plasma power: $300 \mathrm{~W}$, treatment time: $30 \mathrm{~s}$} \\
\hline \multicolumn{3}{|c|}{ Plasma power $(\mathrm{W})$} \\
\hline 150 & 2.31 & 0.45 \\
\hline 300 & 3.26 & 0.55 \\
\hline 600 & 3.94 & 0.57 \\
\hline \multicolumn{3}{|c|}{ Treatment time: $30 \mathrm{~s}$, gas pressure: $0.2 \mathrm{mbar}$} \\
\hline
\end{tabular}

amount of $\mathrm{CO}_{2}$ increases two times as compared to $\mathrm{ACF}_{\text {original }}$ sample, but the amount of $\mathrm{CO}$ evolved is about four times higher than that of the original sample. This indicates the selective destruction/creation of surface oxygen groups by air-MW-plasma treatment, allowing the control of ACF surface functionality. Therefore, the airMW-plasma treatment was optimized as seen below.

\subsubsection{Optimisation of the air-MW-plasma parameters}

Optimisation of the air-MW-plasma parameters was aimed on the regulation of the total amount of surface oxygen groups and the achieving chemical uniformity of the surface groups. The results are summarised in Table 2. The optimisation was carried out by varying the treatment time, the air pressure and the plasma power. The treatment time was limited by $1 \mathrm{~min}$ to avoid the ACF samples burnof. The ACF sample oxidation by air-MW-plasma ( $300 \mathrm{~W})$ was performed in air at 0.2 mbar varying the treatment times. By TPD analysis it was observed that the highest amount of $\mathrm{CO}$ producing groups corresponds to $30 \mathrm{~s}$. The total amount of $\mathrm{CO}_{2}$ was not changed with treatment time.

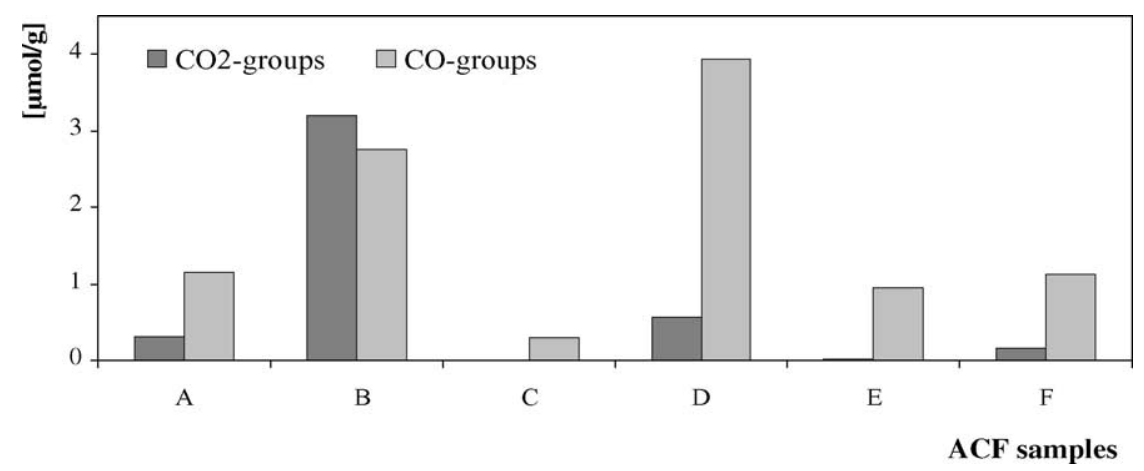

Fig. 1. Bar diagram of total amounts of $\mathrm{CO}_{2}$ and $\mathrm{CO}$ obtained by TPD for different pre-treated $\mathrm{ACF}$ samples. $(\mathrm{A}) \mathrm{ACF}$ original, $(\mathrm{B}) \mathrm{ACF}$ treated in $\mathrm{HNO}$, $(\mathrm{C})$ ACF treated in He at $1273 \mathrm{~K}$, (D) ACF treated in air-MW-plasma, (E) ACF treated in $\mathrm{O}_{2}-\mathrm{MW}$-plasma, and (F) ACF treated in $\mathrm{H}_{2}-\mathrm{MW}$-plasma. 
This can be explained by the low stability of carboxylic groups which were probably destroyed within the first seconds of the treatment. The best result on variation of air pressure was obtained for the pressure of 0.2 mbar. At lower pressure of $0.01 \mathrm{mbar}$, the number of ionized reactive species was probably too low for the oxidation of $\mathrm{ACF}$ in $30 \mathrm{~s}$ [22]. On the other hand, our attempts to increase the air pressure up to 2 mbar failed due to the problems with plasma initiation and its stability. To optimise the plasma power, ACF samples were treated during $30 \mathrm{~s}$ under the air pressure of $0.2 \mathrm{mbar}$ at 150,300
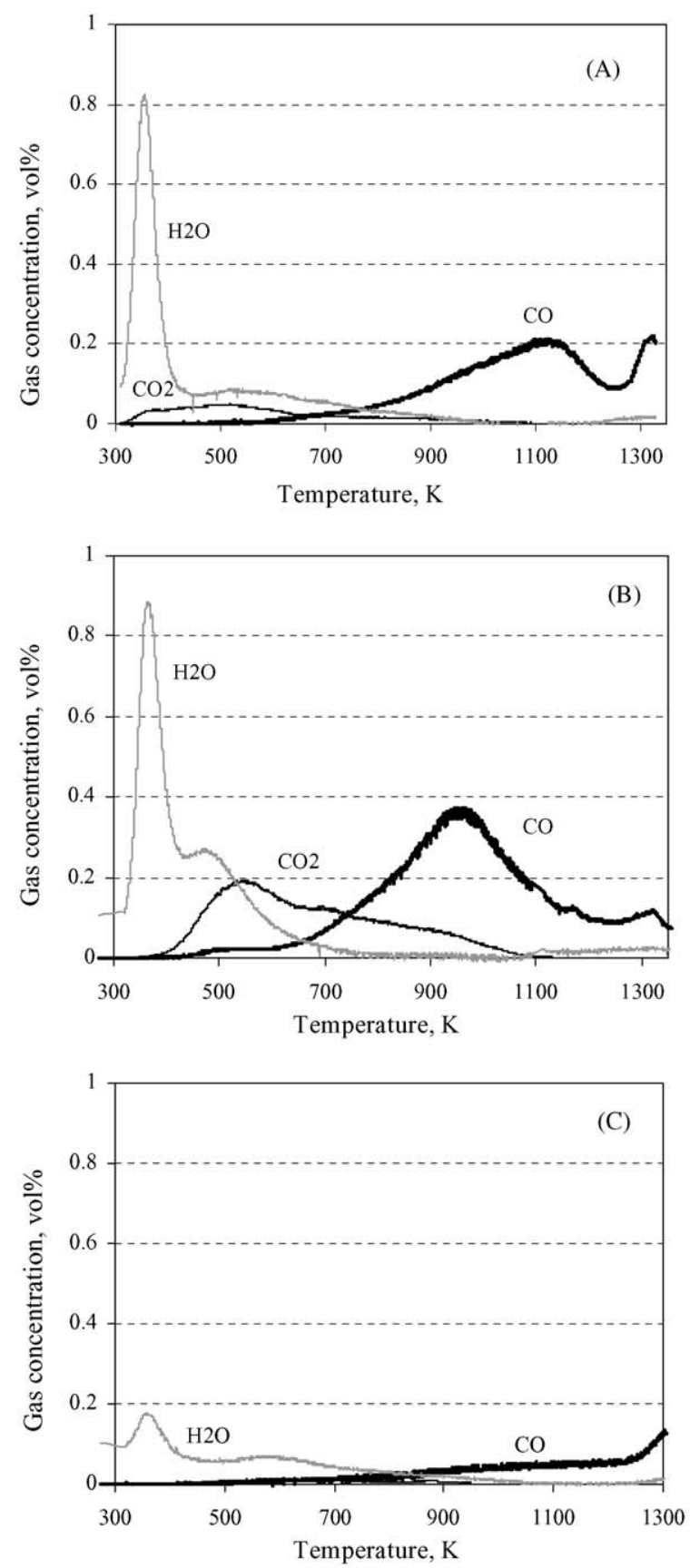

and $600 \mathrm{~W}$. The biggest amounts of $\mathrm{CO}$ and $\mathrm{CO}_{2}$ producing groups correspond to the plasma power of $600 \mathrm{~W}$, since an increased number and energy of ionised reactive species leads to a higher ACF surface oxidation.

\subsubsection{The TPD profiles}

The TPD profiles of non-treated and treated ACF samples were examined to understand the nature of surface oxygen groups contributing to the $\mathrm{CO}$ and $\mathrm{CO}_{2}$ evolved during TPD runs. The results are presented in Fig. 2. The TPD profiles show that the groups producing $\mathrm{CO}_{2}$ are less stable then the
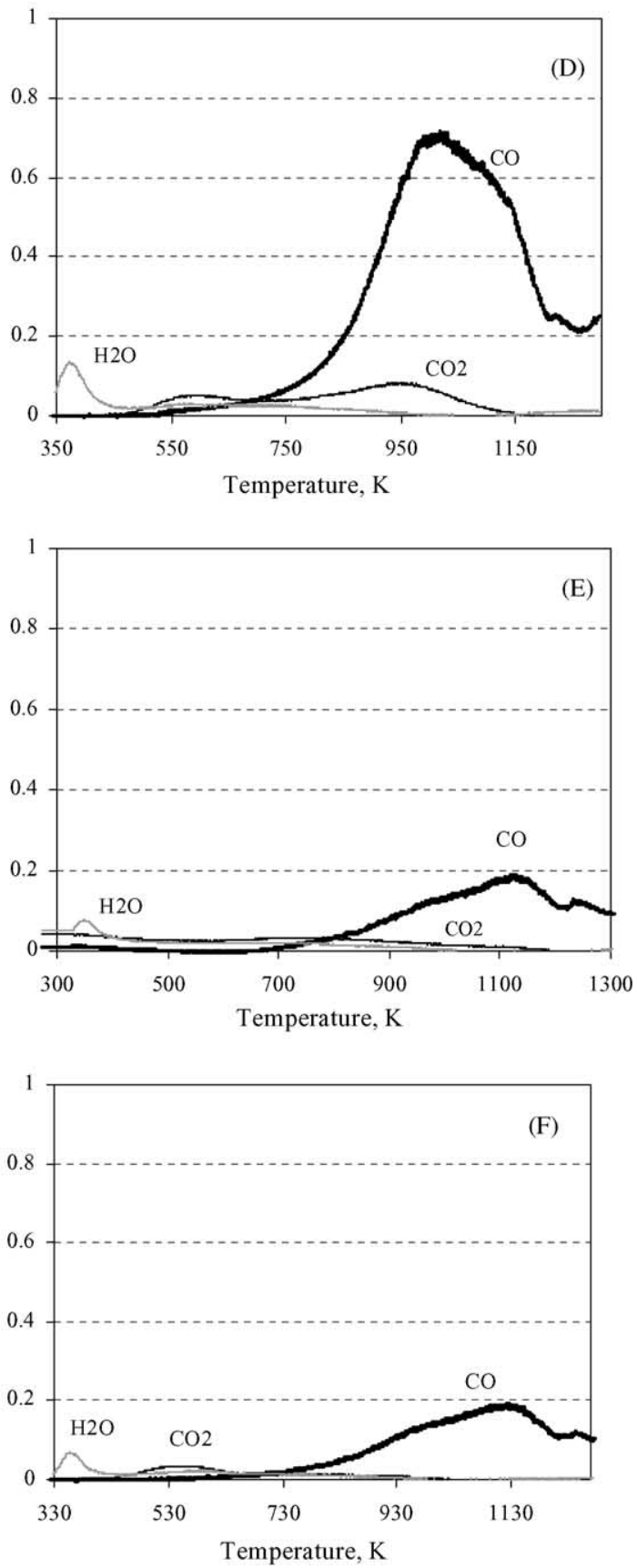

Fig. 2. TPD profiles of ACF samples $(0.05 \mathrm{~g}$, He: $20 \mathrm{ml} / \mathrm{min}, 10 \mathrm{~K} / \mathrm{min})$ after different pre-treatments. (A) ACF original, (B) $\mathrm{ACF}$ treated in $\mathrm{HNO}{ }_{3}$, (C) $\mathrm{ACF}$ treated in $\mathrm{He}$ at $1273 \mathrm{~K}$, (D) ACF treated in air-MW-plasma, (E) ACF treated in $\mathrm{O}_{2}-\mathrm{MW}$-plasma, and (F) ACF treated in $\mathrm{H}_{2}-\mathrm{MW}$-plasma. 
groups producing $\mathrm{CO}$ since they start to decompose at about $400 \mathrm{~K}$. The profile of the non-treated $\mathrm{ACF}_{\text {original }}$ sample (Fig. 2A) consists of $\mathrm{CO}_{2}$ overlapping peaks with maxima at 350 and $540 \mathrm{~K}$ and of broad $\mathrm{CO}$ peak centered at about $1100 \mathrm{~K}$. The first $\mathrm{CO}_{2}$ peak accompanied by the high $\mathrm{H}_{2} \mathrm{O}$ peak can be assigned to elimination of adsorbed $\mathrm{CO}_{2}$ $[12,15,16]$. The $\mathrm{CO}_{2}$ peak at $540 \mathrm{~K}$, which is also accompanied by $\mathrm{H}_{2} \mathrm{O}$ peak with maximum at $500 \mathrm{~K}$, can be attributed to the carboxylic group's decomposition $[6,11,39]$. The left broad shoulder of the CO peak may correspond to the decomposition of phenolic groups, which is known to take place around $873-973 \mathrm{~K}$. The maximum at $1100 \mathrm{~K}$ of the $\mathrm{CO}$ peak is assigned to the carbonyl and quinone groups' destruction $[6,40]$.

The TPD profile of the ACF after $\mathrm{HNO}_{3}$ wet oxidation is presented in Fig. 2B. It follows that the $\mathrm{HNO}_{3}$ treatment increases the acidity of ACF surface. This is reflected in the increased amount of $\mathrm{CO}_{x}$ evolved besides the appearance of some new peaks. Thus, the presence in the $\mathrm{CO}_{2}$ spectra of intensive peak at $540 \mathrm{~K}$ accompanied by $\mathrm{H}_{2} \mathrm{O}$ peak as well as
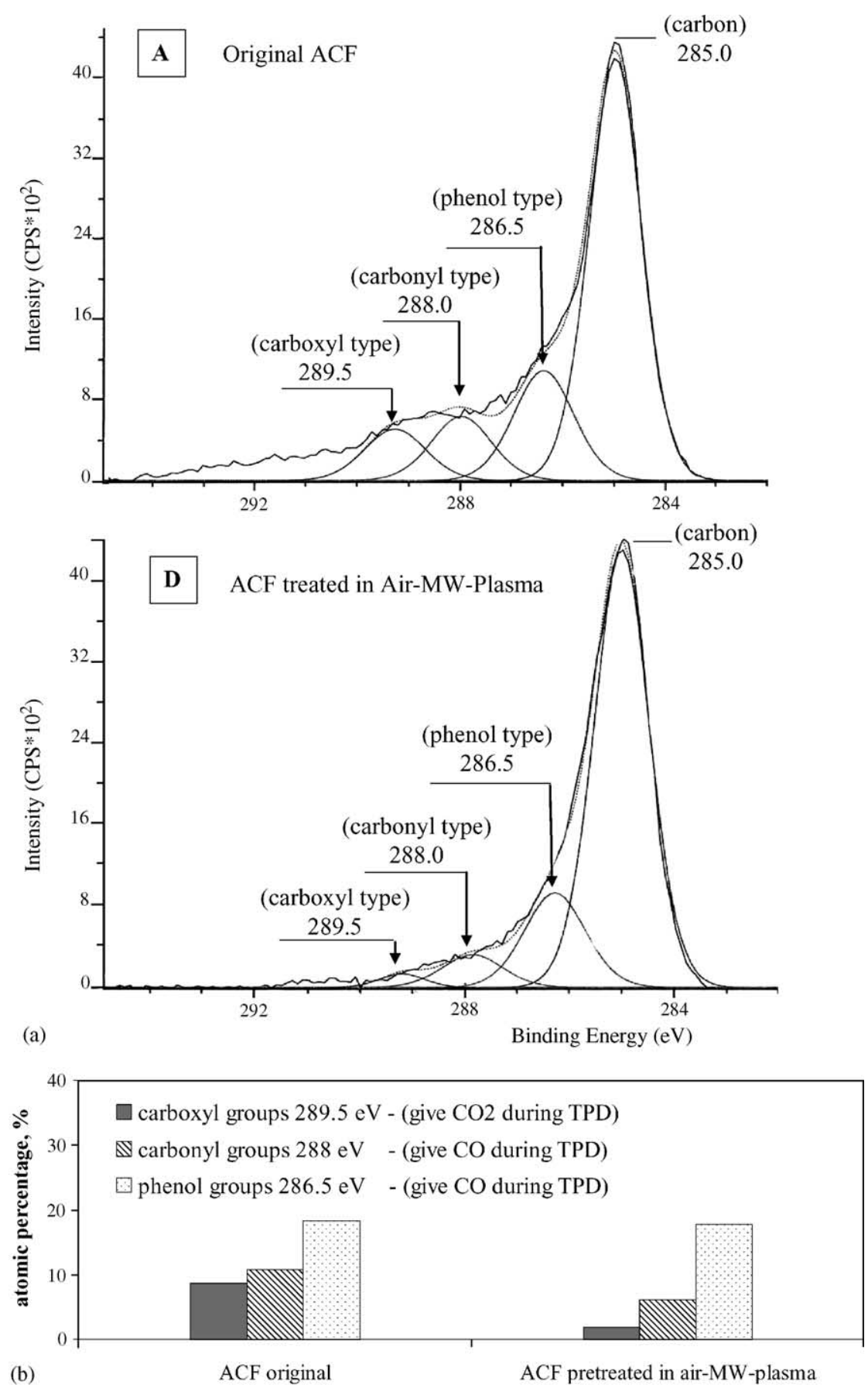

Fig. 3. (a) C1s XPS spectrums of original (A) and air-MW-plasma treated (D) ACF samples. (b) Bar diagram of the surface concentration of functional groups determined by XPS for non-treated and air-MW-plasma treated ACF samples. 
the appearance of $\mathrm{CO}_{2}$ peak at $900 \mathrm{~K}$, can be caused by carboxylic group's decomposition at about $500 \mathrm{~K}$ with the formation of more stable carboxylic anhydride groups. The latter groups are known to decompose at about $700-870 \mathrm{~K}$ with simultaneous formation of $\mathrm{CO}$ and $\mathrm{CO}_{2}[6,11,39]$. The $\mathrm{CO}_{2}$ peak observed at about $700 \mathrm{~K}$ indicates the presence of surface lactone oxygen groups $[6,11,40,41]$. At the same time the large symmetric $\mathrm{CO}$ peak centred at $950 \mathrm{~K}$ can be attributed to decomposition of carboxyl anhydride groups (700-870 K), phenolic $(900 \mathrm{~K})$ and carbonyl/quinone groups $(1100 \mathrm{~K})[6,11,40]$. The TPD profile of the ACF sample treated in He at high temperature (Fig. 2C) confirms the almost complete elimination of oxygen containing functional groups during this treatment.

The TPD profile of air-MW-plasma treated ACF sample (Fig. 2D) is presented by the small $\mathrm{CO}_{2}$ peak at $540 \mathrm{~K}$ (carboxylic groups) and $950 \mathrm{~K}$ (carboxyl anhydride groups) and by a broad intensive peak of $\mathrm{CO}$ with a maximum at $\sim 950 \mathrm{~K}$. This maximum is composed by $\mathrm{CO}$ derived from the decomposition of phenolic and carboxyl anhydride groups. At the same time the contribution of carboxyl anhydride groups in this $\mathrm{CO}$ peak cannot be significant considering the stoichiometry of $\mathrm{CO}$ and $\mathrm{CO}_{2}$ produced from carboxylic anhydride groups. The high shoulder of $\mathrm{CO}$ at about $1130 \mathrm{~K}$ was attributed to the relatively thermostable carbonyl and quinone groups [6,11,39-41].

The TPD profiles of $\mathrm{O}_{2}-\mathrm{MW}$-plasma (Fig. 2E) and of $\mathrm{H}_{2}$-MW-plasma (Fig. 2F) show CO peaks at $950 \mathrm{~K}$ (phenolic groups) and at $1130 \mathrm{~K}$ (carbonyl and quinone groups). The general trend of the CO TPD profiles obtained for $\mathrm{O}_{2}$ - and $\mathrm{H}_{2}-\mathrm{MW}$-plasma treated samples was similar to the profile of the non-treated $\mathrm{ACF}_{\text {original }}$ sample. This contrasts the CO TPD profiles of the ACF treated in air-MW-plasma and of the $\mathrm{ACF}_{\mathrm{HNO}_{3}}$ sample, which are different to the $\mathrm{ACF}_{\text {original }}$. This fact suggests the different nature of surface oxygen groups.

\subsubsection{XPS analysis}

XPS analysis was used for the analyses of the ACF functionality $[15,42,43]$ after different treatments. XPS spectra obtained for original and air-MW-plasma treated ACF samples (Fig. 3a(A and D)) reveal the carbon of graphitic type $(285 \mathrm{eV})$, phenolic $(286.5 \mathrm{eV})$, carbonyl $(288 \mathrm{eV})$ and carboxylic $(289.5 \mathrm{eV})$ groups. Moreover, the tendency of predominant phenolic groups on the ACF treated by MW-plasma, as seen by TPD, is further confirmed. At the same time, the relative amounts of different oxygen groups observed by XPS do not correspond to those found by TPD (see Fig. 3b). This discrepancy in the quantities of the surface functional groups obtained by XPS and TPD is due to the different thickness of the surface layer analyzed. XPS can penetrate up to a few nanometres, giving information involving the over layer (external surface) of the sample. The TPD reaches the whole sample volume [44]. Therefore, the comparison of XPS with the TPD results indicates the difference between the over layer in relation to the bulk of the material.
Table 3

Characteristics of the $\mathrm{Pd} / \mathrm{ACF}$ catalysts prepared from $\mathrm{Na}_{2} \mathrm{PdCl}_{4}$ precursor

\begin{tabular}{llllll}
\hline Catalyst & Palladium & & & Treatment \\
\cline { 2 - 3 } & $\begin{array}{l}\text { Dispersion } \\
(\%)\end{array}$ & $\begin{array}{l}d \\
(\mathrm{~nm})\end{array}$ & & Of the support & Of the catalyst ${ }^{\mathrm{a}}$ \\
\hline $5 \% \mathrm{Pd} / \mathrm{ACF}$ & 63.0 & 1.8 & & Original & - \\
$5 \% \mathrm{Pd} / \mathrm{ACF}$ & 54.0 & 2.1 & & $\mathrm{HNO}_{3}$ & - \\
$4 \% \mathrm{Pd} / \mathrm{ACF}$ & 51.0 & 2.2 & & Air-MW-plasma & - \\
$4 \% \mathrm{Pd} / \mathrm{ACF}$ & 29.0 & 3.8 & & Air-MW-plasma & $\mathrm{H}_{2}-\mathrm{MW}$-plasma \\
4\%Pd/ACF & 27.0 & 4.0 & Air-MW-plasma & $\mathrm{O}_{2}-\mathrm{MW}$-plasma \\
\hline
\end{tabular}

${ }^{a}$ Before reduction in $\mathrm{H}_{2}$.

\subsection{Deposition of Pd via ion-exchange}

Two different Pd precursors were examined for the deposition. The $\mathrm{Na}_{2} \mathrm{PdCl}_{4}$ was used to anchor the $\mathrm{Pd}$ as anion. The $\left[\mathrm{Pd}\left(\mathrm{NH}_{3}\right)_{4}\right] \mathrm{Cl}_{2}$ complex was used to deposit $\mathrm{Pd}$ in cationic form. The results obtained for the anionic complex of Pd are presented in Table 3. The air-MW-plasma causes the particles sintering decreasing the metal dispersion from $63 \%$, in the case of non-treated sample, to $51 \%$ for air-MWplasma treated ACF sample. The same trend was observed for the $\mathrm{HNO}_{3}$ pre-treated $\mathrm{ACF}$ support $\left(\mathrm{ACF}_{\mathrm{HNO}_{3}}\right)$. The attempt to apply the catalyst post-treatment in $\mathrm{H}_{2}-$ or $\mathrm{O}_{2-}$ MW-plasma to eliminate the traces of chloride ions results in the twofold increase of the diameters of Pd particles and in a concomitant 50\% reduction in the Pd dispersion. This result indicates that MW-plasma under mild conditions is able to induce metal sintering.

The data obtained for the Pd deposition from the $\left[\mathrm{Pd}\left(\mathrm{NH}_{3}\right)_{4}\right] \mathrm{Cl}_{2}$ complex are summarised in Table 4 . The airMW-plasma pre-treatment of ACF support doesn't influence the diameter and dispersion of the anchored Pd particles in comparison with Pd deposited on the $\mathrm{ACF}_{\mathrm{HNO}_{3}}$ support. To form catalytically active dispersed metal, it is usually necessary to reduce the catalyst before reaction. In our case to decompose the anchored Pd cationic complex and to eliminate the ammonium traces, the catalyst post-treatment by $\mathrm{O}_{2}-\mathrm{MW}$-plasma was applied. In Table 4 it is shown that the diameter of $\mathrm{Pd}$ particles deposited on $\mathrm{ACF}_{\text {original }}$ is strongly increased during the plasma treatment (the metal dispersion was reduced more than three times). This was not the case for the Pd/ACF catalyst prepared from the air-MWplasma pre-treated support, since the change of the diameter

Table 4

Characteristics of the Pd/ACF catalysts prepared from $\left[\mathrm{Pd}\left(\mathrm{NH}_{3}\right)_{4}\right] \mathrm{Cl}_{2}$ precursor

\begin{tabular}{llllll}
\hline Catalyst & \multicolumn{2}{l}{ Palladium } & & Treatment & \\
\cline { 2 - 3 } & $\begin{array}{l}\text { Dispersion } \\
(\%)\end{array}$ & $\begin{array}{l}d \\
(\mathrm{~nm})\end{array}$ & & Of the support & Of the catalyst $^{\mathrm{a}}$ \\
\hline $2.5 \% \mathrm{Pd} / \mathrm{ACF}$ & 41.0 & 2.7 & Original & - \\
$2.5 \% \mathrm{Pd} / \mathrm{ACF}$ & 47.0 & 2.4 & & $\mathrm{HNO}_{3}$ & - \\
$2.0 \% \mathrm{Pd} / \mathrm{ACF}$ & 45.0 & 2.5 & & Air-MW-plasma & - \\
$2.5 \% \mathrm{Pd} / \mathrm{ACF}$ & 12.0 & 9.1 & & Original & $\mathrm{O}_{2}-\mathrm{MW}$-plasma \\
$2.0 \% \mathrm{Pd} / \mathrm{ACF}$ & 31.0 & 3.2 & Air-MW-plasma & $\mathrm{O}_{2}-\mathrm{MW}-$ plasma \\
\hline
\end{tabular}

${ }^{\text {a }}$ Before reduction in $\mathrm{H}_{2}$. 


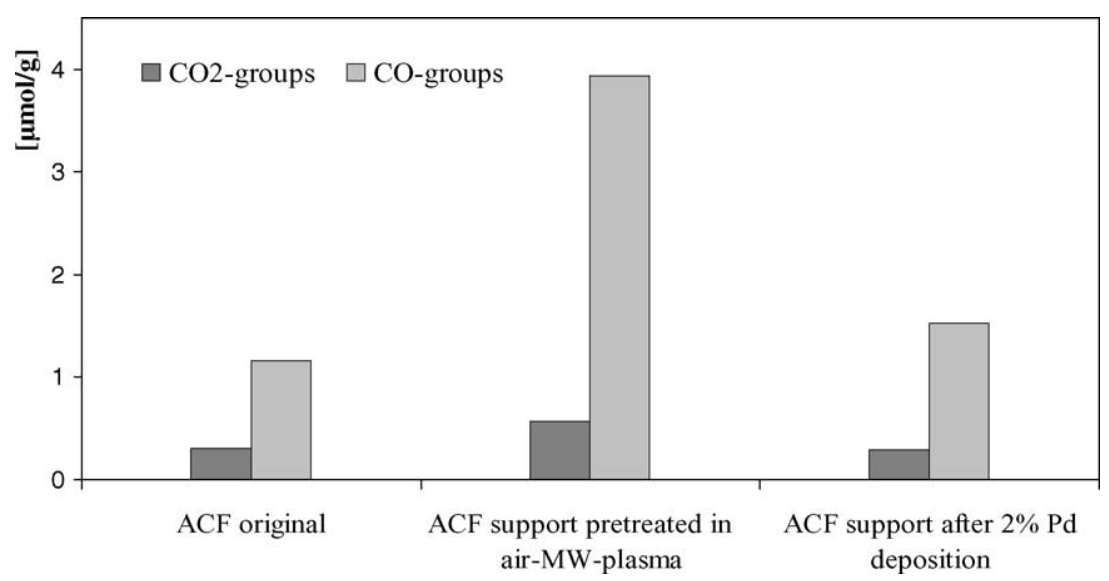

Fig. 4. Bar diagram of $\mathrm{CO}_{2}$ and $\mathrm{CO}$ evolved during the TPD for the non-treated ACF, the air-MW-plasma pre-treated ACF and after Pd deposition on it from $\mathrm{Pt}\left(\mathrm{NH}_{3}\right)_{4} \mathrm{Cl}_{2}$ complex.

of Pd particles was negligible and the high metal dispersion was retained. This result indicates a feasibility of air-MWplasma pre-treatment for a high Pd dispersion on ACF.

Fig. 4 presents total amounts of $\mathrm{CO}$ and $\mathrm{CO}_{2}$ formed during the TPD of non-treated $\mathrm{ACF}_{\text {original }}$ support in comparison with the ACF pre-treated by air-MW-plasma before and after Pd deposition. As compared to the original ACF support, the surface acidity is strongly increased by the air-MW-plasma treatment and is presented by $\mathrm{CO}$ and $\mathrm{CO}_{2}$

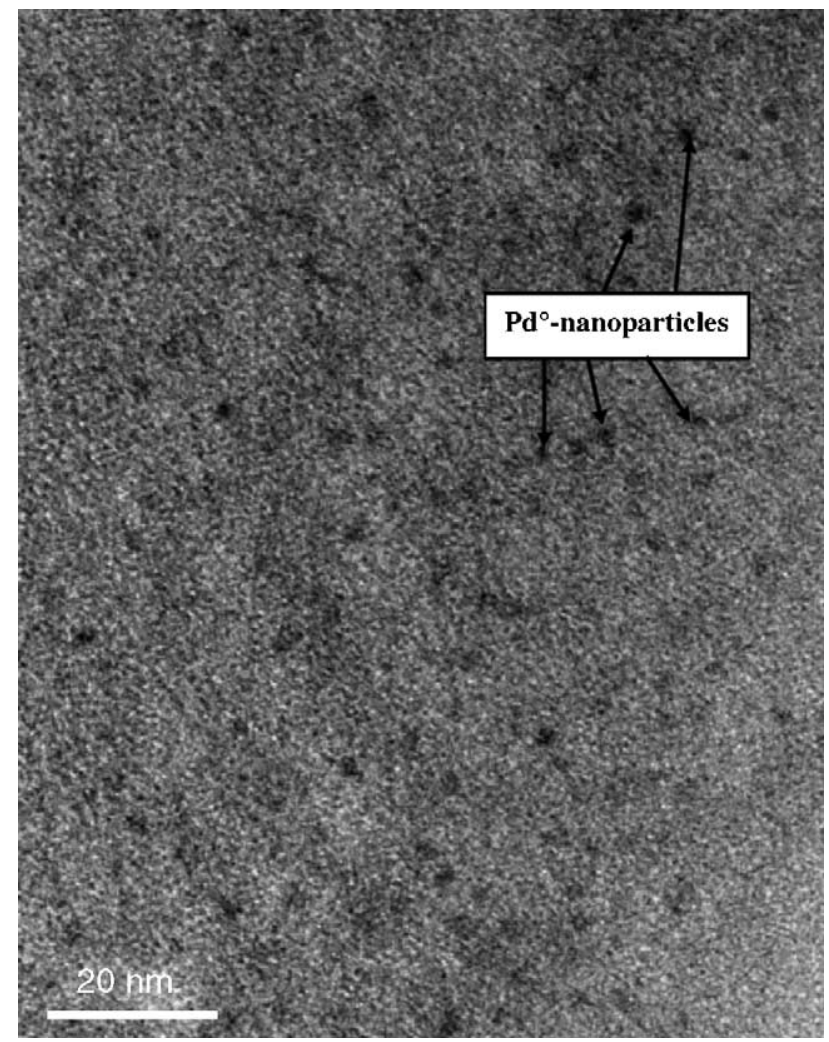

Fig. 5. HRTEM image of $2 \% \mathrm{Pd} / \mathrm{ACF}$ catalyst: the ACF support pre-treated in air-MW-plasma $\left[\mathrm{Pd}\left(\mathrm{NH}_{3}\right)_{4}\right]^{2+}$ complex decomposed in $\mathrm{O}_{2}-\mathrm{MW}$-plasma, the catalyst reduced in $\mathrm{H}_{2}(100 \mathrm{ml} / \mathrm{min}, 373 \mathrm{~K}, 30 \mathrm{~min})$. producing surface groups with the ratio of $6: 1$. The significant decrease of the surface acidity with a majority in $\mathrm{CO}$ producing groups is observed after $\mathrm{Pd}$ deposition. This indicates that $\mathrm{Pd}$ is anchored by ion-exchange with surface phenolic groups. It was shown [11] that phenolic groups contrary to carboxylic surface groups are responsible for the strong cation's anchoring to the carbon surface. The phenolic groups interact with the $\left[\mathrm{Pd}\left(\mathrm{NH}_{3}\right)_{4}\right] \mathrm{Cl}_{2}$ precursor remaining their cationic form:

(C) $-\mathrm{OH}+\mathrm{Pd}^{2+} \rightarrow$ C $-\mathrm{O}^{-} \mathrm{Pd}^{2+}+\mathrm{H}^{+}$

At contrast, the interaction of $\left[\mathrm{Pd}\left(\mathrm{NH}_{3}\right)_{4}\right] \mathrm{Cl}_{2}$ solution with the less stable carboxylic groups, leads to surface decarboxylation and reduction of $\mathrm{Pd}(\mathrm{II})$ to $\mathrm{Pd}(0)$ :

(C) $-\mathrm{COOH}+\mathrm{Pd}^{2+} \rightarrow$ (C) $+\mathrm{Pd}^{0}+\mathrm{H}^{+}+\mathrm{CO}_{2} \uparrow$

During the reductive activation of the catalyst in $\mathrm{H}_{2}$ at $573 \mathrm{~K}$, the former particles serve as nucleation centers for the formation of bigger agglomerates upon surface migration, resulting in coalescence. Formation of big $\mathrm{Pd}$ agglomerates leads to a decline in metal dispersion and could be avoided applying cold MW-plasma. At low temperatures the sintering is less pronounced and high $\mathrm{Pd}$ dispersion is achieved. For $2 \% \mathrm{Pd} / \mathrm{ACF}$ catalyst a $\mathrm{Pd}$ dispersion of $\sim 45 \%$ was obtained.

The TEM analysis confirms the Pd dispersion and shows the Pd clusters with a mean diameter of $\sim 2.5 \mathrm{~nm}$ on the ACF supports (see Fig. 5).

\section{Conclusions}

1. The low-pressure air-MW-plasma is an efficient method of surface modification of the ACF increasing the surface acidity within less than 1 min treatment without affecting the fibre morphology and strength.

2. Selective removal of the carboxylic groups from the ACF surface by the air-MW-plasma allows keeping the 
phenolic groups intact on the ACF surface ensuring Pd metal particles deposition with a high dispersion.

3. Palladium was deposited on ACF from $\left[\mathrm{Pd}\left(\mathrm{NH}_{3}\right)_{4}\right] \mathrm{Cl}_{2}$ solution via ion-exchange with the protons of phenolic surface groups. Surface phenolic groups were able to chemically anchor Pd in cationic form, leading after reduction in $\mathrm{H}_{2}$ to small $\mathrm{Pd}^{\circ}$ nanoparticles $(<3 \mathrm{~nm})$.

4. Heating of the Pd/ACF catalysts in $\mathrm{H}_{2}$ at $573-773 \mathrm{~K}$ is necessary to reduce $\mathrm{Pd}(\mathrm{II})$ to $\mathrm{Pd}^{\circ}$. This reduction can be also achieved by the $\mathrm{H}_{2}-\mathrm{MW}$-plasma treatment within $1 \mathrm{~min}$, which is favourable in regard of energy consumption.

\section{Acknowledgments}

The authors acknowledge the Swiss National Science Foundation and the Swiss Commission of Technology and Innovation (CTI, Bern) for the financial support. The work of Mr. E. Casali for the SSA measurements and Mr. N. Xanthopoulos for the XPS analysis is highly appreciated.

\section{References}

[1] S.R. de Miguel, J.I. Vilella, E.L. Jablonski, O.A. Scelza, C. SalinasMartinez de Lecea, A. Linares-Solano, Appl. Catal. A: Gen. 232 (2002) 237.

[2] R. Fu, Y. Lu, W. Xie, H. Zeng, Carbon 36 (1998) 19.

[3] D.A. Bulushev, L. Kiwi-Minsker, I. Yuranov, E.I. Suvorova, P.A. Buffat, A. Renken, J. Catal. 210 (2002) 149.

[4] M.C. Macias Perez, C. Salinas Martinez de Lecea, A. Linares Solano, Appl. Catal. A: Gen. 151 (1997) 461.

[5] E. Joannet, C. Horny, L. Kiwi-Minsker, A. Renken, Chem. Eng. Sci. 57 (2002) 3453.

[6] J.L. Figueiredo, M.F.R. Pereira, M.M.A. Freitas, J.J.M. Orfao, Carbon 37 (1999) 1379.

[7] M. Domingo-Garcia, F.J.L. Garzon, M.J. Perez-Mendoza, J. Colloid Interface Sci. 248 (2002) 116.

[8] C. Moreno-Castilla, M.V. Lopez-Ramon, F. Carrasco-Marin, Carbon 38 (2000) 1995.

[9] R.-R.F. Radovic, L.R., in: T.P.A. (Ed.), Chemistry and Physics of Carbons, Marcel Dekker, New York, 1997, p. 243.

[10] J.S. Noh, J.A. Schwarz, Carbon 28 (1990) 675.

[11] D.A. Bulushev, I. Yuranov, E.I. Suvorova, P.A. Buffat, L. KiwiMinsker, J. Catal. 224 (2004) 8.

[12] G.S. Szymanski, Z. Karpinski, S. Biniak, A. Swiatkowski, Carbon 40 (2002) 2627.

[13] J.M. Calo, D. Cazorla-Amoros, A. Linares-Solano, M.C. RomanMartinez, C. Salinas-Martinez De Lecea, Carbon 35 (1997) 543.

[14] S. Shin, J. Jang, S.-H. Yoon, I. Mochida, Carbon 35 (1997) 1739.
[15] J.P. Boudou, J.I. Paredes, A. Cuesta, A. Martinez-Alonso, J.M.D. Tascon, Carbon 41 (2003) 41.

[16] J.P. Boudou, A. Martinez-Alonzo, J.M.D. Tascon, Carbon 38 (2000) 1021.

[17] A. Cuesta, A. Martinez-Alonso, J.M.D. Tascon, Carbon 39 (2001) 1135 .

[18] M. Domingo-Garcia, F.J. Lopez-Garzon, M. Perez-Mendoza, J. Colloid Interface Sci. 222 (2000) 233.

[19] M. Domingo-Garcia, F.J. Lopez-Garzon, M. Perez-Mendoza, Carbon 38 (2000) 555.

[20] M. Domingo-Garcia, I. Fernandez-Morales, F.J. Lopez-Garzon, C. Moreno-Castilla, M. Pyda, J. Colloid Interface Sci. 176 (1995) 128.

[21] M. Perez-Mendoza, M. Domingo-Garcia, F.J. Lopez-Garzon, Carbon 37 (1999) 1463.

[22] C.U. Pittman Jr., W. Jiang, G.-R. He, S.D. Gardner, Carbon 36 (1998) 25.

[23] J.I. Paredes, A. Martinez-Alonso, J.M.D. Tascon, Carbon 38 (2000) 1183.

[24] J.I. Paredes, A. Martinez-Alonso, J.M.D. Tascon, Carbon 40 (2002) 1101.

[25] J.I. Paredes, A. Martinez-Alonso, J.M.D. Tascon, J. Colloid Interface Sci. 258 (2003) 276.

[26] C. Jones, E. Sammann, Carbon 28 (1990) 509.

[27] C. Jones, E. Sammann, Carbon 28 (1990) 515.

[28] J.-B. Donnet, W.-D. Wang, A. Vidal, M.-J. Wang, Carbon 32 (1994) 199.

[29] K.S. Ahn, J.S. Kim, C.O. Kim, J.P. Hong, Carbon 41 (2003) 2481.

[30] A. Fukunaga, T. Komami, S. Ueda, M. Nagumo, Carbon 37 (1999) 1087.

[31] M. Nakahara, Y. Sanada, Carbon 33 (1995) 735.

[32] A.M. Diamy, Z. Randriamanantenasoa, J.C. Legrand, M. PolissetThfoin, J. Fraissard, Chem. Phys. Lett. 269 (1997) 327.

[33] J.-C. Legrand, A.-M. Diamy, G. Riahi, Z. Randriamanantenasoa, M. Polisset-Thfoin, J. Fraissard, Catal. Today 89 (2004) 177.

[34] T.L.M. Maessen, D.S.L. Bruinsma, H.W. Kouwenhoven, H. van Bekkum, J. Chem. Soc., Chem. Commun. (1987) 1284.

[35] Y. Zhang, W. Chu, W. Cao, C. Luo, X. Wen, K. Zhou, Plasma Chem. Plasma Process. 20 (2000) 137.

[36] E.A. Dadashova, T.V. Yagodovskaya, E.S. Shpiro, L.A. Beilin, V.V. Lunin, V.V. Kiselev, Kinet. Catal. 34 (1993) 670.

[37] J.-W. Shim, S.-J. Park, S.-K. Ryu, Carbon 39 (2001) 1635.

[38] D.J. Suh, T.-J. Park, S.-K. Ihm, Carbon 31 (1993) 427.

[39] Y. Otake, R.G. Jenkins, Carbon 31 (1993) 109.

[40] U. Zielke, K.J. Huttinger, W.P. Hoffman, Carbon 34 (1996) 983.

[41] B. Marchon, J. Carrazza, H. Heinemann, G.A. Somorjai, Carbon 26 (1988) 507.

[42] D. Youxian, W. Dianxun, S, Mujin, C Chuanzheng, Y. Jin, Compos. Sci. Technol. 30 (1987) 119.

[43] D.T. Cronce, A.N. Mansour, R.P. Brown, B.C. Beard, Carbon 35 (1997) 483.

[44] A.E. Aksoylu, M. Madalena, A. Freitas, M.F.R. Pereira, J.L. Figueiredo, Carbon 39 (2001) 175. 